\title{
Smart Sensing Technologies for Structural Health Monitoring of Civil Engineering Structures
}

\author{
M. Sun, ${ }^{1}$ W. J. Staszewski, ${ }^{2}$ and R. N. Swamy ${ }^{2}$ \\ ${ }^{1}$ Department of Engineering Structures and Mechanics, School of Science, Wuhan University of Technology, Wuhan 430070, China \\ ${ }^{2}$ Department of Mechanical Engineering, Sheffield University, Sheffield S1 3JD, UK
}

Correspondence should be addressed to M. Sun, sunmingqing@yahoo.com

Received 31 August 2009; Revised 7 December 2009; Accepted 3 May 2010

Academic Editor: Jinying Zhu

Copyright $\odot 2010$ M. Sun et al. This is an open access article distributed under the Creative Commons Attribution License, which permits unrestricted use, distribution, and reproduction in any medium, provided the original work is properly cited.

\begin{abstract}
Structural Health Monitoring (SHM) aims to develop automated systems for the continuous monitoring, inspection, and damage detection of structures with minimum labour involvement. The first step to set up a SHM system is to incorporate a level of structural sensing capability that is reliable and possesses long term stability. Smart sensing technologies including the applications of fibre optic sensors, piezoelectric sensors, magnetostrictive sensors and self-diagnosing fibre reinforced composites, possess very important capabilities of monitoring various physical or chemical parameters related to the health and therefore, durable service life of structures. In particular, piezoelectric sensors and magnetorestrictive sensors can serve as both sensors and actuators, which make SHM to be an active monitoring system. Thus, smart sensing technologies are now currently available, and can be utilized to the SHM of civil engineering structures. In this paper, the application of smart materials/sensors for the SHM of civil engineering structures is critically reviewed. The major focus is on the evaluations of laboratory and field studies of smart materials/sensors in civil engineering structures.
\end{abstract}

\section{Introduction}

Civil engineering infrastructure is generally the most expensive national investment and asset of any country. In addition, civil engineering structures have long service life compared with other commercial products, and they are costly to maintain and replace once they are erected [1]. Further, there are few prototypes in civil engineering, and each structure leads to be unique in terms of materials, design, and construction. The most important structures include bridges, high-rise buildings, power utilities, nuclear power plants, and dams. All civil structures age and deteriorate with time. The deterioration is mostly the result of aging of materials, continuous use, overloading, aggressive exposure conditions, lack of sufficient maintenance, and difficulties encountered in proper inspection methods. All of these factors contribute to material and structural degradation as internal and external damages emerge and coalesce, and then evolve and progress.

To ensure structural integrity and safety, civil structures have to be equipped with Structural Health Monitoring
(SHM), which aims to develop automated systems for the continuous monitoring, inspection, and damage detection of structures with minimum labour involvement [2]. An effective SHM system can in real time, and online, detect various defects and monitor strain, stress, and temperature so that the optimum maintenance of the structures can be carried out to ensure safety and durable service life. In general, a typical SHM system includes three major components: a sensor system, a data processing system (including data acquisition, transmission, and storage), and a health evaluation system (including diagnostic algorithms and information management). The first step to set up this system is to incorporate a level of stable and reliable structural sensing capability. So, this paper is mainly related to the first component of the SHM system: the sensing system formed by smart materials/sensors. Smart materials/sensors, such as fibre optic sensors (FOS), piezoelectric sensors, magnetostrictive sensors, and self-diagnosing fibre reinforced structural composites, possess very important capabilities of sensing various physical and chemical parameters related to the health of the structures. Since shape memory alloys and 
magnetorheological fluids are often used as actuators, they are not introduced in this paper.

FOS, for example, are small and therefore do not affect the performance characteristics of civil engineering structures in which they are embedded. A single fibre can efficiently monitor structural performance at various locations by using multiplexed or distributed sensing technologies. They are unperturbed by electromagnetic interference. Optical waves are suitable for long transmission distances of relatively weak signals. Piezoelectric and magnetorestrictive sensors can serve as both sensors and actuators, which make SHM to be an active monitoring system. Furthermore, they can come in a variety of sizes, allowing them to be placed everywhere, even in remote and inaccessible locations, to actively monitor the conditions of various types of structures.

Since the subject matter of SHM has been growing rapidly and significantly over the last few years, the focus of this paper is on a critical state-of-the-art review of various applications of the above smart materials/sensors in SHM of civil engineering structures. It is beyond the scope of the paper to describe all the relevant theories involved, or to report all of practical applications examples. The paper covers the major aspects of fibre optic sensors, piezoelectric sensors, self-diagnosing fibre reinforced composites, and magnetostrictive sensors for applications in civil engineering. Finally, the conclusions of this study are briefly reported.

\section{Fibre Optic Sensors (FOSs)}

There are several methods to classify FOS. The first method of classifying FOS is based on the light characteristics (intensity, wavelength, phase, or polarization etc.) modulated by the parameters to be sensed. The second method classifies an FOS by whether the light in the sensing segment is modified inside or outside the fiber (intrinsic or extrinsic). FOS can also be classified as local (Fabry-Perot FOS or longgauge FOS etc.), quasidistributed (fibre Bragg grating) and distributed sensors (Brillouin-scattering-based distributed FOS) depending on the sensing range [3]. This method of classification is adopted here. FOS are generally surface mounted on existing structures, or embedded in newly constructed civil structures, including bridges, buildings, and dams, to yield information about strain (static and dynamic), temperature, defects (delamination, cracks and corrosion), and concentration of chloride ions. The obtained data can be used to evaluate the safety of both new-built structures and repaired structures, and diagnose location and degree of damages. In this section, the application of FOS in monitoring of strain, displacement and defects in civil engineering structures is reviewed. Other relevant details may be found in early reviews of FOS by Merzbacher et al. [4], Ansari [5] and Leung [6].

2.1. Monitoring of Strain and Displacement. Laboratory studies have clarified some basic sensing properties of FOS in applications for civil engineering structures. De Vires et al. [7] reported that Fabry-Perot FOS output signals compared

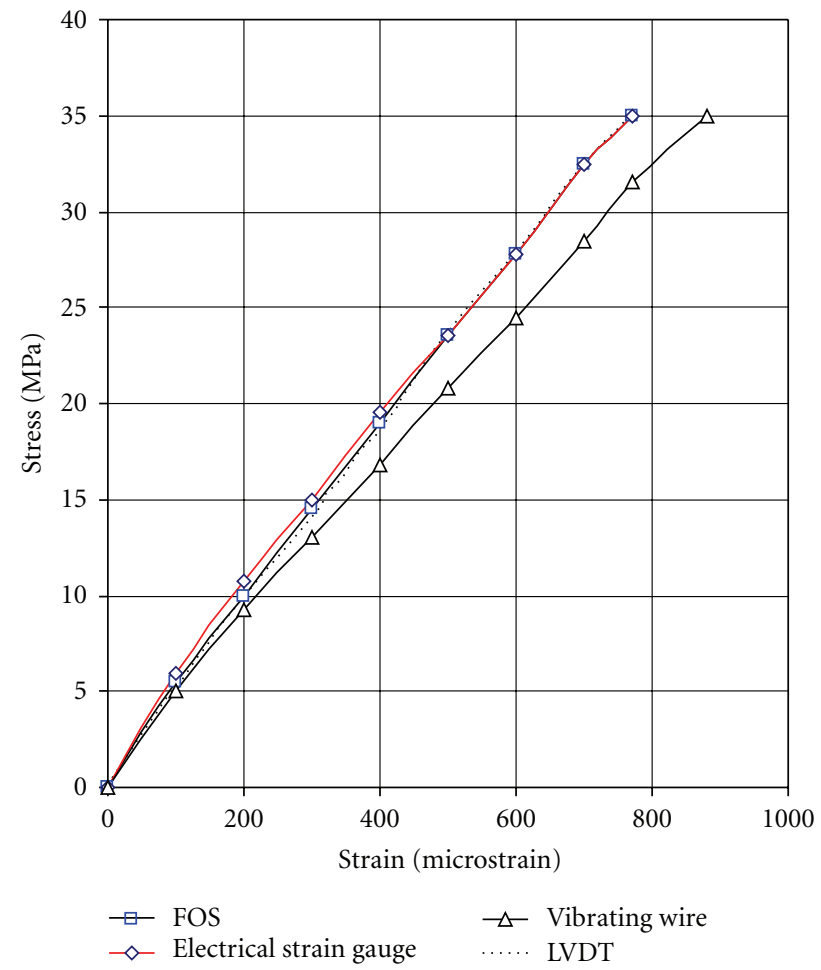

FIGURE 1: Comparsion of concrete strains with various sesors [8, 9].

well with the output signals obtained from collocated strain gauge in the test of a concrete cross-beam specimen, and FOS had a much better signal-to-noise ratio than the strain gauge. Quirion and Ballivy $[8,9]$ have evaluated the performance of the Fabry-Perot FOS when it was embedded in concrete cylinders. Figure 1 shows the measurements obtained with FOS compared to those by vibrating-wire gauges, electrical strain gauges, and LVDT when the level of stress is slightly over $40 \%$ of concrete compressive strength. It can be observed that measured strains with the FOS are in good agreement with those measured by the electrical strain gauge and LVDT. Zhang et al [10] conducted a repeated loading test on a concrete slab with embedded FOS. Four million cycles at a frequency of $2 \mathrm{~Hz}$ and $3 \mathrm{~Hz}$ were applied. The sensors survived the 4 million loading cycles at a strain amplitude of $2000 \mu \varepsilon$, and showed good response to dynamic loading. Delepine-lesoille et al. [11] designed a kind of composite-made wave-like sensor body, which could make the stiffness of optical fiber and concrete match to one another. Thus, strain concentrations were reduced, and no theoretical calibration factor had to be taken into account. It also achieved continuous bonding to the concrete and allowed a symmetrical response under tensile and compressive loadings whatever the contact condition was.

Zeng et al. [12] measured the strain distributed along a $1.65-\mathrm{m}$ reinforced concrete beam using one single-mode fibre, called as Brillouin-scattering-based distributed FOS which could measure temperature and strain simultaneously. Strain measurement accuracy reached $\pm 5 \mu \varepsilon$ with the resolvable distance of $5 \mathrm{~cm}$. Chen et al. [13] compared two 
kinds of distributed sensors: Electric Time Domain Reflectometry cable sensor that was based on the propagation of electromagnetic waves in an electrical cable and Brillouinscattering-based distributed FOS. They were mounted near the surface of the $80 \%$ scale beam-column reinforced concrete assembly. Results showed that the cable sensor could measure a significant change of strain locally while distributed FOS were good candidates for the measurement of slowly-varying strain over a long distance. The cable sensor measured a strain distribution in seconds or shorter and therefore applicable for dynamic signal measurements. However, FOS required several minutes to complete one measurement. Wu et al. [14] installed Brillouin-scatteringbased distributed FOS to evaluate the performance of a full-scale prestressed concrete girder. Compared with the measurement results from strain gage, FOS gave good results for tension strain measurement. But, FOS for compression strain measurement included a relatively large error, especially when the compression strain was small.

In aspect of the practical applications of FOS, Beddington Trail Bridge in Calgary, Canada was the first bridge in the world to be monitored by a fibre Bragg grating (FBG) sensing system and the first highway bridge to use carbon fibre reinforced polymer composite (CFRP) prestressing tendons in some of its girders. In this bridge, several tendons were equipped with a total of $18 \mathrm{FBG}$ sensors after prestressing in 1993 [15]; 15 of sensors survived and functioned correctly. The relaxation behaviour of prestressing tendons from the combined effects of distressing, concrete creep and shrinkage, dead loads of the bridge deck and the posttensioning was evaluated. They found that there was a higher net strain relaxation in the steel prestressed concrete girders than that in the CFRP tendon, and continuing stress relaxation existed apparently in all girders eight months after the opening of the bridge to traffic. A dynamic truck test showed that these sensors were still operative six years later, and no structural problems were detected [16]. Above all, the more important significance of their study lies in that this project demonstrated the benefits and advantages of merging optic sensing technology, innovative fibre reinforcement materials and structural engineering. The real-time monitoring of FRP reinforcement components can increase user confidence of their application in concrete structures, since there are no current design standards for structures with FRP reinforcements. On the other hand, the optic sensors can be bonded on the surface of the fibre reinforcement bars so that the bars can provide excellent protection of the sensors and their leads, and yield a very convenient means of instrumenting and monitoring civil engineering structures in the field.

Currently, many bridges around the world have been instrumented with FOS sensing system. Benmokrane et al. [17] applied Fabry-Perot FOS to the rehabilitation project of the Joffre Bridge, Quebec, Canada. They were bonded to the CFRP grids and steel girders to monitor the performance of the FRP reinforced structure, strains of the deck and strains of the girder. The results showed that the temperature was the most important factor influencing the strain variation in the bridge deck under service conditions. The field measurements were carried out one year after the opening of the bridge to traffic. Using three 25-ton calibrated trucks to evaluate the strain level in the FRP reinforcements, the measured strains in the FRP reinforcements were less than $20 \mu \varepsilon$, and strains in the steel girder were less than $120 \mu \varepsilon$. Mufti et al. [18] described the procedure of embedding FBG sensors in the Confederation Bridge, Canada, but no data from these sensors have been reported. In Taylor Bridge, a total of 63 FBG sensors and a total of 26 electric strain gauges were bonded to the prestressing CFRP bars to monitor the maximum strain in the reinforcement due to the applied loads. But even though the strain gauges were properly sealed, over $60 \%$ of the electric strain gauges malfunctioned due to excessive moisture resulting from steam curing of the concrete girders. Strains recorded by FBG sensors were less than $15 \mu \varepsilon$ when a 36-ton truck passed the bridge. Besides these, there are some other demonstration projects in Canada undertaken by ISIS. More details can be found in http : / / ww.isiscanada.com / field / main.htm ? field _ projects .htm.

Brönnimann et al. [19] reported the application of FBG in two bridges in Switzerland. In the Storchenbrucke in Winterthur, FBG were adhered to CFRP wires to measure the strain of suspension cables. FBG had been working reliably within the strain level around $2000 \mu \varepsilon$ for three years by March 1st, 1999. The other was a pedestrian bridge with CFRP as the prestressing cable, where the optical fibre was embedded in CFRP wire during the pultrusion of CFRP. Most of the FBG sensors embedded inside suffered from the high curing temperature of the resin of about $170-190^{\circ} \mathrm{C}$ and the high level prestressing strain of $8000 \mu \varepsilon$, although two of them failed due to debonding. They have satisfactorily monitored the strain evolution within the cables and the anchor head during the prestressing process and afterwards for over a year.

Inaudi and Vurpillot [20] developed a new method to retrieve the global deformation and curvature of bridges using their long-gauge SOFO sensors. 96 SOFO, with a gauge length of $4 \mathrm{~m}$, were embedded in the first two spans of the Versoix Bridge. Based on the physical model they proposed, global horizontal and vertical deformations of a total length of over $100 \mathrm{~m}$ were calculated when the static load was applied on the bridge, and the values matched well with that measured by the dial gauges. In a similar way, the curvature variations of the Lutrive Highway Bridge with truck circulation were monitored. In addition, field displacement monitoring was performed in some phases of construction of the Siggenthal Bridge, such as concreting of different arch, removal of the scaffolding and free standing phase of the arch [21].

Fuhr et al. [22] described the FOS installation process in a $67 \mathrm{~m}$ long steel truss bridge spanning the Winooski River in Waterbury, Vermont; 46 FOS were embedded in the deck but only one sensor was broken. They [23] have developed a frequency-domain-based multiplexing sensor to measure pressure and vibration simultaneously. The hydroelectric dam on the Winooski River in Vermont was an example where this kind of FOS was incorporated into. During the initial low-power testing of the generation equipment, an 
abnormal frequency was found, which indicated that a main gear in the power train was out-of-round [24].

Ou and Zhou [25] reported their work on FOS applied in bridge monitoring in mainland China, especially in Harbin Institute of Technology. FBG sensors were implemented in over 10 practical bridges to monitor strain, stress and temperature. For example, 40 FBG strain sensors, 10 FBG temperature sensors, and 96 FBG cable sensors have been successfully installed in Yonghe Bridge in Tianjin City, China. The strain of the main beam, the stress of the prestressed reinforcement and the cables were monitored during bridge load test [26]. Liu and Jiang [27] developed a SHM system for the first cable-stayed bridge across the Yangtze River in China. Both the FBG-based overloading vehicle recognition system and remote real-time cable force monitoring system operated successfully.

Habel et al. [28] integrated quasi-distributed FOS into rock anchors to monitor the strain distribution along the fixed anchor length inside the rock. In order to improve the stability of the EDER-dam, Germany, a vertical anchoring of the dam was performed. The quasi-distributed FOS was made by inserting fibre splices at regular intervals along the optical fibre, each segment working as a strain gauge based on time-of-flight measurement. As the anchor was fabricated, an FOS-equipped aramid rod was placed in the centre of the anchor. Data from FOS indicated that only 2 to $2.5 \mathrm{~m}$ of the fixed anchor length of $10 \mathrm{~m}$ contributed to the bond, and this value varied with the changing water level. The sensing system had survived in such a harsh environment with anchor forces of $4500 \mathrm{kN}$.

Fiber optic monitoring system has also been introduced into civil structures under extreme exposure conditions. For example, Newhook et al. [29] have designed a FOS health monitoring program for the Hall wharf. It was in both the splash and tidal zones, and subjected to thermal ranges of $-35^{\circ} \mathrm{C}$ in winter and $+35^{\circ} \mathrm{C}$ in summer. Unfortunately the survivability rate of FOS was not high. After the sensors were embedded for one year, 10 of the 17 sensors were not functioning. The main reason for failures of sensors was associated with connector failures. The manufacturing flaw, salt crystals or other dirt caused the failure of the bonding agent holding the connector sheath to the fibre optic cable.

In general civil buildings, Fuhr et al. [30] installed FOS in a five-storey, 65000 square feet concrete structure, named the Stafford Medical Building of Vermont University, to monitor stresses incurred during the construction phase and monitoring of concrete curing as well as internal crack sensing. Kwon et al. [31] used Brillouin-based distributed FOS to measure temperature distribution in a building construction. The optical fibre with a length of $1400 \mathrm{~m}$ was installed on the surface of the building. And the temperature of surface changed normally up to $4^{\circ} \mathrm{C}$ through one day.

Among all smart sensors, only FOS have been used exclusively to monitor so many practical civil structures effectively. These applications show that FOS are more promising for SHM of civil engineering structures than other smart sensors. Of course, the monitoring of the local strain of key components of civil engineering structures and displacement of the whole structure is only one of the

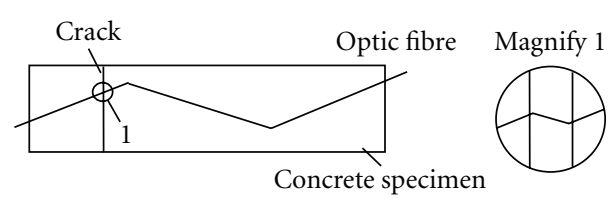

FIGURE 2: The "zig-zag" layout of optic fibre at the bottom of the specimen [33]

important contents of the SHM system. The local strain can be used to detect the working conditions of components. The data obtained are compared to initial design values of the structures under factored gravity and live loads to examine if the structures are in the status expected.

2.2. Detection of Defects. Application of FOS in SHM of civil engineering structures involves detection of defects such as cracks, corrosion, and delamination. Crack detection is dependent on loss of optical transmission, and FOS-based ultrasonic wave methods. Detection of corrosion, $\mathrm{pH}$, and chloride content is mainly dependent on colour modulation.

Rossi and Le Maou [32] used optical fibres to monitor the shape of the crack tip in concrete. The operation of their method was based on the breakage of fibres as a crack propagating in concrete reached the optical fibres. However, its use was limited if one did not know crack location in advance since the polymeric coating of the fibre in the cracking zone had to be removed before embedding it in concrete. Leung et al. [33] developed a method of monitoring flexural cracks in a concrete beam. The optical fibre was laid in a "zig-zag" form at the bottom of the concrete beam (see Figure 2). When a crack opens in the structure, the optical fibre intersecting the crack at an angle other than $90^{\circ}$ had to bend. The sudden bending of the fibre at the crack resulted in an optical power loss. For this method to work, the fibre should be free to slide inside the concrete. Preliminary experimental results on concrete specimens showed that the proposed approach could detect the crack opening width as small as $0.1 \mathrm{~mm}$. Recently, their method was used to monitor multiple flexural cracks under static loading, crack monitoring under cyclic loading as well as the detection of shrink crack under restraint in concrete beams [34]. However, this method was not feasible to detect cracks parallel to the surface of the structure. Elvin et al. [35] proposed a FOSs based technique for the monitoring of delamination that was parallel to the surface of the structure. In their method, a moving load was applied on the measured beam with one arm of the Servo-Homodyne interferometer attached below the surface. The output of the interferometer represented the optical phase shift and was proportional to the integrated strain along the embedded fibre. When the position of loading moved, the curve of the phase change versus load position could be obtained. It was found that the phase change was very sensitive to both the delamination location and size.

Gu et al. [36] employed a quasi-distributed FOS similar to that used by Habel et al. [28] for measurement of crack opening widths along the whole length of reinforced concrete 
beams under four-point bending. A linear relationship between the crack opening width and the loss of the optical intensity was concluded. It was found that the embedded FOS could keep a good accounting of the cracks during fatigue loading and monotonic loading.

FOS can also be utilised as ultrasonic/acoustic sensors to detect cracks. Chen and Ansari [37] reported a fibre optic distributed pulse-echo system for monitoring defects in a concrete beam. A PZT transmitter was used for the generation of stress waves. The FOS was adhered to the surface of the beam for sensing the echoed ultrasonic signals. Preliminary laboratory study showed that this system had detected two simulated flaws within the beam based on the resonance method. Chen and Farhad [38] developed an FOS acoustic sensor. It could monitor the acoustic emissions from cracks in a concrete structure. Betz et al. [39] reported that FBG sensors had the ability to sense ultrasonic Lamb waves.

As a whole, major investigations in this field are preliminary laboratory studies. The method proposed by Rossi and Le Maou [32] requires a priori knowledge of crack location; techniques of Leung et al. [33], and Gu et al. [36] can perform distributed or quasi-distributed detection of cracks which is normal to the fibre direction; the approach of Elvin et al. [35] is only for horizontal cracks. Ultrasonic wave methods can work without the limitation of the direction of crack. Previous studies have exhibited the capability of ultrasonic waves to detect delamination, voids, and cracks in concrete structures [40-42].

With respect to corrosion detection, Fuhr and Huston [43] reported their rebar corrosion detection technique using FOS based on colour modulation. When the fibre was in close proximity $(<10 \mathrm{~mm})$ to the corroding rebar, the input light from the fibre at its end or at a windowed region was colour modulated. Then the modulated signal travelled back down the fibre and was sensed via standard spectroscopy. By comparing the corroded and uncorroded spectra, peak wavelength shift along with the intensity of the light signal revealed the presence and the level of corrosion. The experimental result coming from this sensor was in agreement with the conventional monitoring methods of steel corrosion. The main limitation of this sensor was its small signal-to-noise ratio. Tennyson et al. [44] examined the loop strain of a concrete column using long-gauge FOS so that steel corrosion in concrete could be monitored as the internal corrosion causes the columns to swell. But, experimental results have not been reported. Wang et al. [45] made use of the microbending characteristic of longperiod optical grating (LPFG) to monitor the steel corrosion in concrete structures. As the radial expansion of the steel resulting from the steel corrosion led to the bending of LPFG, the curvature of LPFG could be obtained by analyzing the change of spectrum, and then the steel corrosion depth could be measured. This method was independent of the variety in temperature, strain, and refractive index owing to the inimitable spectrum characteristic of LPFG.

Cosentino et al. [46] developed a fibre optical chloride sensor using $\mathrm{Ag}_{2} \mathrm{CrO}_{4}$ powder bonded to the end of an optical fibre. This sensor worked when the chloride changed a reddish-brown $\mathrm{Ag}_{2} \mathrm{CrO}_{4}$ to white $\mathrm{AgCl}$. The colour change caused the intensity of light propagating through the fibre to increase. They reported that chloride concentration was in proportion to the slope of the light output versus time plots. But the drawback of this sensor was that it was not a reversible sensor, so it was difficult to detect increasing and decreasing chloride concentrations continuously.

Michie et al. [47] reported a distributed moisture and $\mathrm{pH}$ detection scheme which used a cable with surface-mounted hydrogel polymer coating and optical fibre. The hydrogel absorbed water and swelled in aqueous media so that the loss of an optical fibre was modulated. The system was tested in a simulated experiment to examine the extent of grout fill in a posttensioned concrete structure tendon duct. In their experiment, voided regions with no water were identified. By selection of the appropriate gel system as the indicator which was responsive to changes in $\mathrm{pH}$, this type of sensor could detect the areas where the $\mathrm{pH}$ of the grout dropped. The decrease in $\mathrm{pH}$ would expose the tendons to potential corrosion. Grahn et al. [48] developed a FOS system for the measurement of $\mathrm{pH}$ in concrete consisting of $\mathrm{pH}$-indicator dyes immobilized in a highly hydrophilic polymer matrix. Change in $\mathrm{pH}$ was indicated by a colour change of the dye/polymer system. The sensor system displayed long-term stability even in aggressive media of $\mathrm{pH}$ 12-13.

2.3. Concluding Remarks of FOS. FOS have the sensing capability both in the laboratory and in the field as local, quasi-distributed (or multiplexed) and distributed sensors. Various applications of FOS in civil engineering structures, such as monitoring of strain, displacement, vibration, cracks, corrosion, and chloride ion concentration have been developed. Especially, field tests on bridges, hydroelectric projects, and some civil buildings have proved to be effective. FOS can work in the harsh natural environment, and have large sensing scope, joining with low transmission loss and antielectromagnetic interference, so they are very advantageous to perform SHM of civil engineering structures. However, because the study of FOS in civil engineering structures is relatively recent, and the earliest reports date back only to 1989, their long-term sensing ability under field experimental conditions due to aging has to be investigated further. They are fragile in some configurations, and the damage is difficult to repair when embedded. The optical connection parts, which connect the embedded optical fibre with the outer data recording system, are also weak elements of the FOS system. Field examples using FOS to detect defects and damages have not yet been fully investigated and reported.

\section{Piezoelectric Sensors}

Based on electrical-mechanical transformation, piezoelectric materials exhibit simultaneous actuator/sensor behaviour. There are various types of piezoelectric materials: piezoelectric ceramics, piezoelectric polymers, and piezoelectric composites. More recently, piezoelectric sensors were introduced into SHM of civil engineering structures as an active sensing technology based on the measurement of electrical impedance and elastic waves. 
3.1. Electrical Impedance-Based SHM Method. When a PZT patch attached to a structure is driven by a fixed, alternating electric field, a small deformation is produced in the PZT wafer and the attached structure. Since the frequency of the excitation is very high, the dynamic response of the structure reflects only that of a very local area near the sensor. The response of that local area to mechanical vibration is transferred back to the PZT wafer in the form of an electrical response. When a crack or damage causes change of the mechanical dynamic response, it is manifested in the electrical impedance response of the PZT wafer [49]. Therefore, structural damages can be monitored indirectly through measurement of the electrical impedance of the PZT sensors.

Ayres et al. [50] bonded two PZT patches to a quarterscale steel truss bridge joint for the acquisition of the electrical impedance when the damage was simulated by loosening bolts in the structure. The real part of admittance (reciprocal of impedance) was extracted as a function of the exciting frequency. Admittance was sensitive to the local damage near the PZT, but was insensitive to damage away from the sensor. Similar tests have been done by Park et al. [51]. However, besides the electrical impedance method, Park et al. have also used Lamb wave method to detect damages in a steel bridge component. Park et al. [52] have monitored the cracking process of a small-scale composite-reinforced masonry concrete wall under uniaxial compression using this method. Besides it, the stability of the impedance-based technique was examined with a civil pipe joint under significant temperature variation in the range of $25-75^{\circ} \mathrm{C}$. The impedance changed as temperature varied. However, when damage was introduced, the temperature made little influence on the qualitative detection result. They [53] also developed a compensation technique to minimise the effects of temperature on impedance measurement. The compensation procedure was based on the reconstruction of the damage metric, which minimised the impedance drifts due to temperature. Further, Yang et al. [54] studied the influence of environmental conditions, temperature and thickness of the bonding layer between PZT patches and aluminum plate on the repeatability of electrical admittance signatures. Experimental investigations revealed that under various environmental conditions electrical admittance was stable for a monitoring period of up to one and a half years. The effect of bonding could be neglected even for thickness up to two-thirds of the PZT patch's thickness, provided that the excitation frequency did not exceed $100 \mathrm{kHz}$. Above this frequency, the adverse effect of thick (larger than one-third of the PZT thickness) bonding was obvious. By comparing the admittance at the high frequency range $(200-1000 \mathrm{kHz})$, a temperature change triggered the shift of the PZT resonance peaks. Some vital experimental observations in [54] have been successfully verified by means of simulation of the PZT-structure interaction using the commercially available software, ANSYS version 8.1 [55].

Soh et al. [56] carried out an impedance-based health monitoring and damage detection using PZT patches on a prototype reinforced concrete (RC) bridge. The bridge was instrumented with $11 \mathrm{PZT}$ patches at key locations. The patches were scanned for the acquisition of the impedance data at various stages during the loading process. The results showed that the surface mounted PZT patches were very sensitive to the development of cracks in concrete in their local vicinity, but were insensitive to those farther away. Tseng and Wang [57] performed two sets of experimental tests on the concrete beams $(100 \mathrm{~mm} \times 100 \mathrm{~mm} \times 500 \mathrm{~mm})$ instrumented with PZT transducers. The root mean-square deviation (RMSD) of the real part of electric admittance increased with the progression of damage on the surface of the specimen or in the depth of the specimen. Lim et al. [58] developed a new method for identifying equivalent structural parameters (stiffness, mass, and damper) from the measured admittance signatures, whereby the identified parameters were used for damage characterization. The method has been applied to detect damages in a truss, a beam and a concrete cube successfully. Comparing with the conventional RMSD, their method gave much better insight into the damage mechanism whereas RMSD gave little clue about the nature of the damage mechanism. While, Wen et al. [59] measured the equivalent circuit parameters of PZT, such as the static compliance, the static resistance, the dynamic inductance, the dynamic resistance, and the dynamic compliance and so forth, to monitor stress and temperature in concrete structures.

The impedance method has used a self-sensing actuator concept: a single PZT acts both as actuator and sensor. The qualitative nature of this technique makes it very accessible for everyone, since it does not require any background knowledge in order to interpret the simple output. Its sensing area is the vicinity of the sensor, which helps to isolate the effect of damage from other far-field changes in loading, stiffness and boundary conditions. But, it is a qualitative method because various types of damage such as cracks, corrosion and delamination will all affect the mechanical impedance similarly, which makes the distinction between each type of damage very difficult. So, once the impedance-based technique detects damage, other quantitative techniques have to be used to determine the exact nature of the damage. Otherwise, the impedance analyzers employed are expensive until now, an efficient and inexpensive methodology for electrical impedance measurement is necessary in the future.

3.2. Elastic Wave-Based SHM Method. Wang et al. [60] and $\mathrm{Wu}$ and Chang [61] conducted preliminary studies to detect the debonding between the reinforcing bars and concrete with PZT patches bonded on the steel rebar. A 5-peak burst ultrasonic wave with peak value of $200 \mathrm{~V}$ was applied on the actuator. Amplitude and time of arrival of the first peak were recorded and analysed. They found that the amplitude of the received signals increased in a linearly proportional manner to the debonding size of the steel bar from the concrete. The arrival time remained constant while the rebar was elastic, but increased as the bar yielded. They [62] also used PZFlex software to simulate the response of the sensor as parameters in RC structures such as crack width, size of debonding and position of the rebar varied. Numerical simulation showed that cracks in RC structures did not affect the sensor output. 
When both debonding damage and cracks existed in the structures, debonding damage dominated the output signals. And the depth of the concrete section did not affect the detection of debonding damage.

Kawiecki [63] studied the feasibility of nondestructive damage detection by an array of piezotransducers bonded to the surface of a concrete block. Structural damages were simulated by placing objects with different mass at the surface of the tested specimens. Experimental results indicated that there was a strong correlation between the size and location of a simulated damage and the variation of the magnitude of its transfer function and shift of natural frequency. Anomalies in these signals were repeatable and had distinct characters when they were caused by damages.

Saafi and Sayyah [64] developed an active damage interrogation (ADI) technique to detect delaminations between the repaired concrete and CFRP. As shown in Figure 3, an array of PZT transducers was attached on to the CFRP laminate. The beam has dimensions of $100 \times 150 \times 900 \mathrm{~mm}$ with a notch of $10 \times 25 \times 100 \mathrm{~mm}$ to initiate and accelerate the delamination process. The ADI system actively interrogated the structure through broadband excitation of the transducers. The sensor signals were digitized and the transfer function, cumulative average delta, and damage index of actuator/sensor pairs were computed. Figure 4 shows the relationship between damage index and load. As load increased, the increase of damage index was obvious in Zone 1, while in Zone 2 and Zone 3 damage index started to increase at $160 \mathrm{kN}$ and $200 \mathrm{kN}$, respectively. So, the process of delamination was detected. The damage was localized with an error of $0.67 \%$.

Sun et al. [65] used PZT patches as sensors or actuators to initiate and receive Rayleigh waves propagating along the surface of concrete beam, and longitudinal waves, shear waves propagating through internal concrete. Results showed that from the velocity of Rayleigh waves and longitudinal waves, both the dynamic modulus of elasticity and dynamic Poisson's ratio of concrete could be calculated. Differences in amplitude of received waves were highly sensitive to the cracking process in concrete due to externally applied loads. Changes in the waveforms could thus reflect the effects of internal microcracking in concrete.

Song et al. [66] have embedded their smart aggregates containing waterproof piezoelectric patches into different types of concrete specimens. The sensor-history damage index matrix and the actuator-sensor damage index matrix were obtained to monitor the time-history and location information of damages in a two-story concrete frame. Their system could also monitor strength of early concrete and impact on the structures. Li et al. [67] reported their research on cement-based 0-3 piezoelectric composites, which had good compatibility with concrete and good piezoelectric properties. Recently, $\mathrm{Lu}$ and $\mathrm{Li}$ [68] employed sensors made with cement-based 0-3 piezoelectric composites and cement-based 1-3 piezoelectric composites to detect the acoustic waves due to crack propagation in concrete. Both of them provided good results on the accumulated events number of the acoustic emission and crack location. Cracks

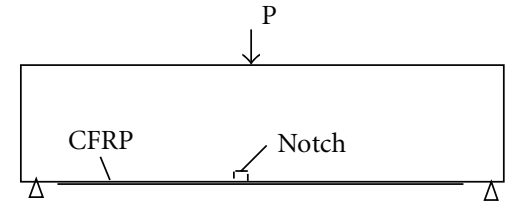

(a)

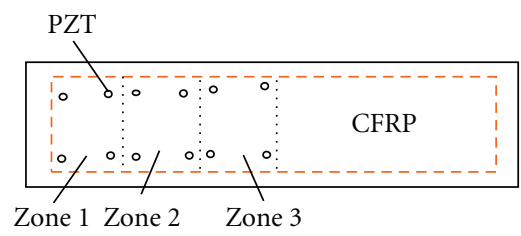

(b)

FIGURE 3: Locations of PZT patches on CFRP bonded on concrete beam [64].

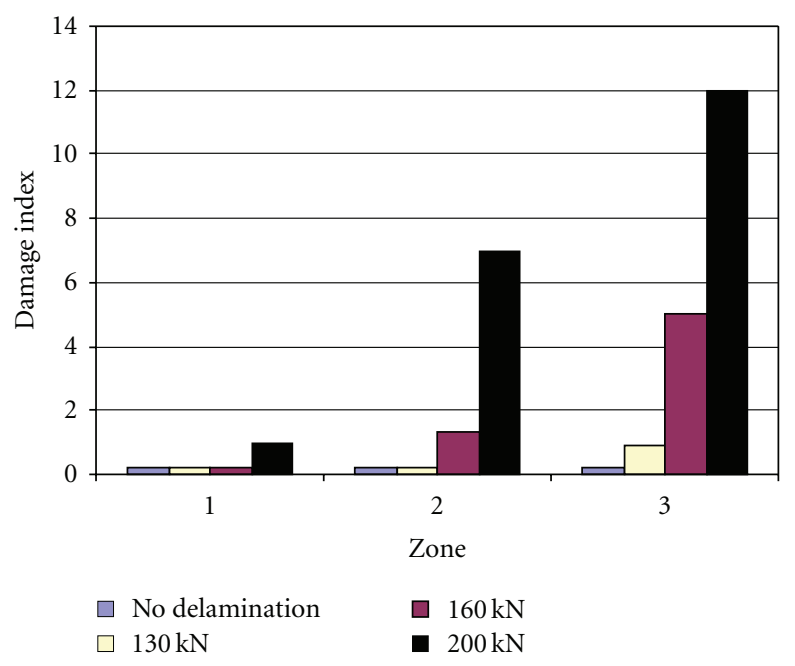

Figure 4: The variation of damage index for zone 1, 2 and 3 with applied load increasing [64].

in reinforced concrete beam were monitored by the encapsulated PZT transducers by Zhao et al. [69]. The damage index calculated according to different central frequency elastic wave energy based on continuous wavelet analysis can correctly express the initiation and development of crack in the reinforced concrete beam.

Elastic wave-based approach can detect larger areas than the impedance-based method. Further, the elastic wavebased method can take advantage of more information of the wave propagation to identify damages, such as amplitude and phase of the transfer function, shift in frequencies, amplitude and the arrival time. This method as well as the electrical impedance-based method, is an active sensing method, while most of the SHM techniques are based on passive sensing diagnostics that rely on passive sensor measurements to determine changes in the condition or environment of the structure. However, further studies are needed to verify the feasibility of piezoelectric sensors monitoring methods based on ultrasonic wave propagation to detect various 


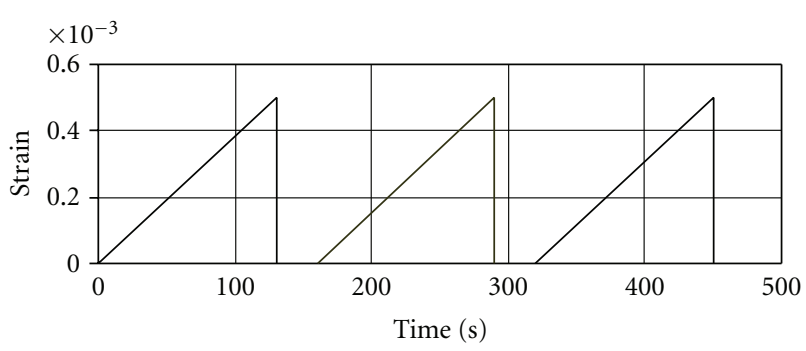

(a)

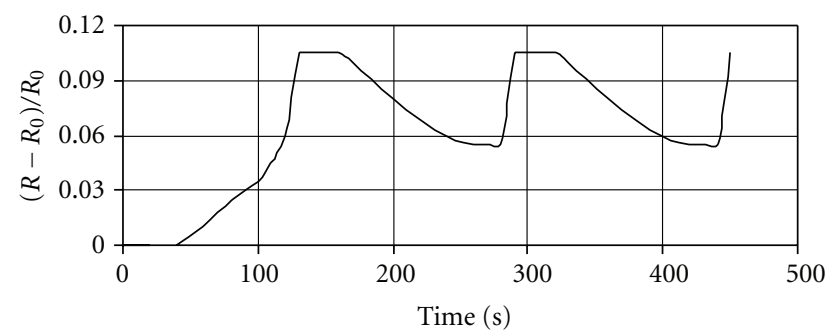

(b)

Figure 5: $\Delta R / R_{0}$ and compressive versus time obtained during cyclic loading for CFRC [70].

defects in real concrete elements and reinforced concrete structures by combining other technologies such as wireless communication and algorithms for detection of the positions of damages and the severity of damages.

\section{Self-Diagnosing Fibre Reinforced Composites}

Self-diagnosing (or self-monitoring) fibre reinforced composites contain an electrical conductive phase such as carbon fibre and conductive powder in the cement or polymer matrix. Table 1 presents the commonly used self-diagnosing fibre reinforced composites and their components. They have the abilities to monitor their own strain, damage, and temperature. Chen and Chung $[70,71]$ have reported that CFRC can sense strain and damage by its change in electrical resistance. Figure 5 shows the fractional change in resistance along the stress axis as well as the strain during repeated compressive loading within the elastic region. Size of mortar specimens was $5.1 \times 5.1 \times 5.1 \mathrm{~cm}$, and the content of short carbon fibre was 0.24 vol\%. As shown in Figure 5, during the first loading, the irreversibly increasing $\Delta R / R_{0}$ is due to the weakening of the fibre-matrix interface; during the second and the subsequent loadings, reversibly decreasing $\Delta R / R_{0}$ during loading is due to fibre push-in, while reversibly increasing $\Delta R / R_{0}$ during unloading is due to fibre pull-out. At high stress amplitude up to failure, resistance increases greatly. CFRP has similar properties as CFRC [72]. Mao et al. [73] divided the resistance variation of CFRC with strain into three stages: reversible sensing stage, balancing stage (the resistance hardly changes in this phase), and rapidly increasing stage, which corresponded to different phases of crack development in CFRC during loading. Mingqing et al. [74] reported Seebeck effect of CFRC, which was the basis of temperature sensing for CFRC and the cement-based thermoelectric materials.
TABLE 1: Components of self-diagnosing fibre reinforced composites.

\begin{tabular}{|c|c|c|}
\hline Name of composites & $\begin{array}{l}\text { Electrical conductive } \\
\text { materials and its } \\
\text { volume content in } \\
\text { the composites }\end{array}$ & Matrix materials \\
\hline $\begin{array}{l}\text { Carbon fibre } \\
\text { reinforced concrete } \\
\text { (CFRC) }\end{array}$ & $\begin{array}{l}\text { Short carbon fibre } \\
(\mathrm{L}<10 \mathrm{~mm},<0.5 \mathrm{vol} \\
\%)\end{array}$ & $\begin{array}{l}\text { Cement, Mortar, } \\
\text { concrete including } \\
\text { admixtures } \\
\text { (methylcellulose, } \\
\text { silica fume et al.) }\end{array}$ \\
\hline $\begin{array}{l}\text { Carbon fiber } \\
\text { reinforced Polymer } \\
\text { (CFRP) }\end{array}$ & $\begin{array}{l}\text { Short carbon fibre } \\
(\mathrm{L}<10 \mathrm{~mm} \text {, } \\
10 \mathrm{vol} \%) \\
\text { Continuous carbon } \\
\text { fibre }(58 \mathrm{vol} \%)\end{array}$ & Resin, curing agent \\
\hline $\begin{array}{l}\text { Carbon fiber glass } \\
\text { fibre reinforced } \\
\text { Polymer (CFGFRP) }\end{array}$ & $\begin{array}{l}\text { Continuous carbon } \\
\text { fibre }(<0.5 \text { vol } \%)\end{array}$ & Resin, curing agent \\
\hline $\begin{array}{l}\text { Carbon powder } \\
\text { dispersed in glass- } \\
\text { fibre-reinforced } \\
\text { plastics (CPGFRP) }\end{array}$ & $\begin{array}{l}\text { Graphite carbon } \\
\text { powders }(0.15 \text { vol } \% \text {, } \\
\text { average particle } \\
\text { diameter }=5 \mu \mathrm{m})\end{array}$ & Resin, curing agent \\
\hline $\begin{array}{l}\text { hybrid carbon fiber } \\
\text { reinforced polymer } \\
\text { (HCFRP)sensors }\end{array}$ & $\begin{array}{l}\text { high modulus } \\
\text { (HM), medium } \\
\text { modulus (MM) and } \\
\text { high-strength (HS) } \\
\text { carbon tows }\end{array}$ & Resin, curing agent \\
\hline
\end{tabular}

L: length

Until now, only some small-scale laboratory studies on smart application of CFRC and CFRP have been conducted. Wen and Chung [75] applied CFRC coatings on the tension and the compression sides of a cement paste beam under flexure. Under cyclic loading and unloading, the resistance of the coating decreased reversibly on the compression face in every cycle, while the resistance increased reversibly on the tension face in every cycle except the first cycle. So, it appears that the CFRC strain-sensing coating was a possible usable form for SHM of concrete structures. Wang et al. [76] found the ultimate load and the stiffness of CFRC-strengthened reinforced concrete $(\mathrm{RC})$ beam are slightly larger than that of the virgin $\mathrm{RC}$ beam. Through the measurement of the electrical resistance change, $\mathrm{RC}$ beams with the thicker CFRC layer had higher sensitivity to stress and fatigue damage. Wang and Chung [77] also applied CFRP coating containing short carbon fibre on cube specimens of mortar to measure the strain. The sensing limits of this sensor were 0 $420 \mu \varepsilon$ in tension and $0-1100 \mu \varepsilon$ in compression respectively. Exceeding these limits was found to cause damages in the coating. It was thus clear that this CFRP coating could not satisfy the requirements for practical applications to monitor the performance of concrete structures in real life.

CFGFRP was designed to be a hybrid of a conductive carbon fibre with a small ultimate elongation value and an insulating glass fibre with a large ultimate elongation value. As shown in Figure 6, during tensile loading, a distinct and significant change in electrical resistance indicated the 


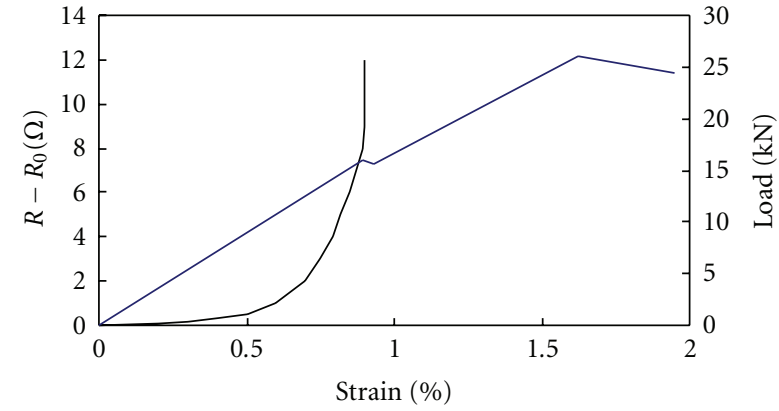

FIGURE 6: Change in electrical resistance with strain increasing [78].

failure of carbon tows. After that, CFGFRP does not fracture suddenly since the load was sustained by the remaining high-elongation glass fibres. So CFGFRP had possibilities of self-diagnosing function without the occurrence of sudden failure. It can be used to give early-warnings of catastrophic failure of structures, and monitor high values of strain through the use of carbon fibres with different ultimate elongation values. A CFGFRP grid has been embedded in the 20th floor slab of the skyscraper known as the Republic Plaza in Singapore, to detect the occurrence of cracks in concrete. CFGFRP has also been used as a security system for security walls with functions of both detecting and preventing burglaries $[78,79]$.

However, the sensitivity of CFGFRP to strain is very low in the strain range from zero to the point just before carbon fibre fracture. After the breakage of carbon tows, CFGFRP can not continue to sense strain or cracks. Therefore, CFGFRP is generally unsuitable for strain monitoring in the small or medium strain range. However, CPGFRP (carbon powder dispersed in glass-fibre-reinforced plastics) prepared by Muto et al. [80], was superior to CFGFRP with respect to their capability of monitoring in the above-mentioned strain range. But CPFGRP suffered from difficulties of mass production and high cost. While, Yang and $\mathrm{Wu}[81]$ employed a new method to improve the sensing capability of CFRP by pulling the impregnated carbon tows repeatedly through a roller with a diameter of $5 \mathrm{~cm}$. Their aim was to preset some microcracks to the carbon tows. Results showed that the pretreatment could enhance the sensitivity of CFRP to strain more than 100 times, especially in a low strain range. Above all, unlike CFGFRP, Yang et al. [82] used three types of carbon tows (high modulus, medium modulus, and highstrength carbon tows, resp.) to design hybrid carbon fiber reinforced polymer (HCFRP) sensors. HCFRP sensors could monitor the whole loading procedure of concrete structures with high sensitivity, including the elastic deformation, the yielding of reinforcing steel bars, and the initiation and propagation of cracks in concrete.

The technique of SHM using self-diagnosing fibre reinforced composites as sensors is a simple technology. One of the most obvious advantages of this type of smart materials is that they work as both structural materials and sensing materials. CFRP and GFRP can be used as reinforcing elements for concrete, as shown in Section 2 of this paper.
CFRC containing small volumes of short fibres possesses higher stiffness, tensile strength and lower drying shrinkage than plain concrete. Thus the incorporation of carbon fibres has not only provided smart abilities, but also improved the mechanical properties of concrete. Laboratory studies have shown that they have the abilities to monitor their own strain, damage and temperature. CPGFRP and HCFRP have better sensitivity than CFGFRP. However, until now, field applications of this kind of smart material in SHM of civil engineering structures have not been developed. Further, the sensing repeatability of self-diagnosing fibre reinforced composites is needed to improve. There are many factors that can affect the repeatability of self-diagnosing fibre reinforced composites, including: (1) distribution state of conductive materials in the matrix; (2) electrical resistance change due to temperature, moisture, and transversal effect; (3) irreversible increase of resistance due to the damages of the sensing materials and interfaces during cyclic loading; and (4) methods of resistance measurement and preparation of materials.

\section{Magnetostrictive Sensors}

Ferromagnetic materials have the properties that, when placed in a magnetic field, they are mechanically deformed. This phenomenon is called the magnetostrictive effect. The reverse phenomenon, in which the magnetic induction of the material changes when the material is mechanically deformed, is called the inverse magnetostrictive effect. Based on these phenomena, Kwun and Bartels [83] invented a type of magnetostrictive sensor $(\mathrm{MsS})$ which could generate and detect guided waves in the ferromagnetic materials under testing without direct physical contact to the material surface. Khazem et al. [84] utilized MsS to inspect suspender ropes on the George Washington Bridge in New York. They launched a pulse of $10 \mathrm{kHz}$ longitudinal guided wave along the length of the suspender, detected the reflected signals from geometric features and defects in the suspender.

$\mathrm{Na}$ and Kundu [85] used MsS for internal inspection of voids and inclusions in concrete-filled steel pipes. It was shown that the MsS system could generate different guided wave modes propagating along the steel pipe; and these waves were sensitive to the defects in the pipe. The received wave amplitudes decreased as the length of voids and inclusions increased. To overcome the major disadvantage of MsS, that is, the relatively low ultrasonic energy transmitted, $\mathrm{Na}$ and Kundu [86] developed a hybrid approach combining PZT and MsS. This method was very effective for steel bar-concrete interface inspection. Bouchilloux et al. [87] measured the stress of the steel cable based on the reverse magnetostrictive effect. The accuracy of the MsS was within $3 \%$; but the perturbation of temperature affected the accuracy. The difference between two extremes of temperature, that is, between $10^{\circ} \mathrm{C}$ and $50^{\circ} \mathrm{C}$, was $6 \%$. Rizzo and Di Scalea [88] used the discrete wavelet transform to extract damage-sensitive features from the signals detected by MsS to construct a multidimensional damage index vector. The damage index vector was then fed to an artificial neural 
network to provide the automatic classification of the size of the notch and the location of the notch of multiwire strands.

MsS can generate different guided wave modes by simply changing the coil or magnet geometry. They can work without any couplants. Guided waves have strong potentials for monitoring because of the capability for long-distance inspections. However, MsS is only suitable for ferromagnetic materials. Relatively low ultrasonic energy with low signal to noise ratio can be transmitted. And the induced energy is critically dependent on the probe proximity to the object being tested.

\section{Concluding Remarks}

Smart materials/sensors are a new development with enormous potential for SHM of civil engineering structures. Some of them are currently being applied in the field, while others are being evaluated under laboratory conditions.

FOS are versatile sensors for SHM applications in civil engineering. Various applications of FOS in civil engineering structures, such as monitoring of strain, displacement, vibration, cracks, corrosion, and chloride ion concentration, have been developed. In particular, field tests reported on bridges, hydroelectric projects, and some civil buildings have been found to be effective. FOS can work in a harsh natural environment, and have large sensing scope, joining with low transmission loss, antielectromagnetic interference and distributed sensing, and so they are advantageous to apply for SHM of civil engineering structures. However, the long-term sensing ability of FOS under field experimental conditions due to aging has not been fully established, and needs to be investigated further. They are fragile in some configurations, and the damage is difficult to repair when embedded. The optical connection parts, which connect the embedded optical fibre with the outer data recording system, are also weak elements of the FOS system. Field examples using FOS to detect defects and damages have not yet been fully investigated and reported.

Piezoelectric sensors can be used as an active sensing technology in the SHM of civil engineering structures based on electrical impedance and elastic wave methods. The impedance method depends on the self-sensing actuator concept. It is a qualitative method. Elastic wavebased approaches can detect larger areas of damage than the impedance-based method, and this method can take advantage of additional information arising from the wave propagation to identify damages. However, further studies have to be carried out to verify the feasibility of this method to detect various defects in real concrete structures and reinforced concrete structures.

Self-diagnosing fibre reinforced composites are also available as sensors and offer a very simple technology for the SHM of civil engineering structures. One of the most obvious advantages of this type of smart materials is that they work as both structural materials and sensing materials. Laboratory studies have shown that they have the abilities to monitor their own strain, damage and temperature. CPGFRP and HCFRP have better sensitivity than CFGFRP. However, the practical applications of this type of smart materials in civil engineering structures are yet to be developed.

MsS can generate different guided wave modes by simply changing the coil or magnet geometry. They can work without any couplants. Guided waves have strong potentials for structural health monitoring because of their longdistance inspection capability. However, it is only suitable for ferromagnetic materials. Relatively low ultrasonic energy with low signal to noise ratio can be transmitted.

SHM system must possess the comprehensive abilities to detect positions and severity of damages. However, until now lots of studies about applications of smart sensors/smart materials in SHM of civil engineering are related to the basic sensing abilities of smart sensors. That is, some damages within structures can be monitored directly using data from sensors, while others can only be detected indirectly through special diagnostic methods. Important civil engineering structures are usually very large. So, many sensors are equipped to make structures sense their health conditions. Wireless transmission and processing the data before transmission will be a useful method to solve the problem of bulk data management in the practical SHM system. And SHM of the practical civil engineering structures will greatly depend on diagnostic algorithms such as inverse problem analysis, artificial neural network, and the expert system. So, real SHM system for civil engineering is the integration of smart sensors/smart materials, data transmission, and advanced diagnostic methods.

\section{Acknowledgments}

The authors would like to acknowledge the Chinese Scholarship Council (CSC) for the financial support to the first author during his research study at Sheffield University in UK. The work is also supported by the National Natural Science Foundation of China (no. 50878170) partly.

\section{References}

[1] K. P. Chong, "Health monitoring of civil structures," Journal of Intelligent Material Systems and Structures, vol. 9, no. 11, pp. 892-898, 1999.

[2] F. K. Chang, "Structural health monitoring: a summary report on the first international workshop on structural health monitoring," in Proceedings of the 2rd International Workshop on Structural Health Monitoring, F. K. Chang, Ed., pp. 3-11, Technomic Publishing Company, Lancaster, UK, September 1997.

[3] B. Culshaw and J. Dakin, Eds., Optical Fiber Sensors. Applications, Analysis, and Future Trends, vol. 4, Artech House, London, UK, 1996.

[4] C. I. Merzbacher, A. D. Kersey, and E. J. Friebele, "Fiber optic sensors in concrete structures: a review," Smart Materials and Structures, vol. 5, no. 2, pp. 196-208, 1996.

[5] F. Ansari, "State-of-the-art in the applications of fiber-optic sensors to cementitious composites," Cement and Concrete Composites, vol. 19, no. 1, pp. 3-19, 1997.

[6] C. K. Y. Leung, "Fiber optic sensors in concrete: the future?" NDT and E International, vol. 34, no. 2, pp. 85-94, 2001. 
[7] M. De Vries, M. Nasta, V. Bhatia et al., "Performance of embedded short-gage-length optical fiber sensors in a fatigueloaded reinforced concrete specimen," Smart Materials and Structures, vol. 4, no. 1A, pp. 107-113, 1995.

[8] M. Quirion and G. Ballivy, "Concrete strain monitoring with Fabry-Pérot fiber-optic sensor," Journal of Materials in Civil Engineering, vol. 12, no. 3, pp. 254-261, 2000.

[9] M. Quirion and G. Ballivy, "Laboratory investigation on Fabry-Pérot sensor and conventional extensometers for strain measurement in high performance concrete," Canadian Journal of Civil Engineering, vol. 27, no. 5, pp. 1088-1093, 2000.

[10] B. Zhang, B. Benmokrane, J.-F. Nicole, and R. Masmoudi, "Evaluation of fibre optic sensors for structural condition monitoring," Materials and Structures, vol. 35, no. 250, pp. 357-364, 2002.

[11] S. Delepine-Lesoille, E. Merliot, C. Boulay, L. Quétel, M. Delaveau, and A. Courteville, "Quasi-distributed optical fibre extensometers for continuous embedding into concrete: design and realization," Smart Materials and Structures, vol. 15, no. 4, pp. 931-938, 2006.

[12] X. Zeng, X. Bao, C. Y. Chhoa et al., "Strain measurement in a concrete beam by use of the Brillouin-scattering-based distributed fiber sensor with single-mode fibers embedded in glass fiber reinforced polymer rods and bonded to steel reinforcing bars," Applied Optics, vol. 41, no. 24, pp. 51055114, 2002.

[13] G. Chen, B. Xu, R. D. McDaniel, X. Ying, D. J. Pommerenke, and $\mathrm{Z}$. Wu, "Distributed strain measurement of a largescale reinforced concrete beam-column assembly under cyclic loading," in Smart Structures and Materials: Sensors and Smart Structures Technologies for Civil, Mechanical, and Aerospace Systems, vol. 5765, article 55 of Proceedings of SPIE, pp. 516527, San Diego, Calif, USA, March 2005.

[14] Z. Wu, B. Xu, K. Hayashi, and A. Machida, "Distributed optic fiber sensing for a full-scale PC girder strengthened with prestressed PBO sheets," Engineering Structures, vol. 28, no. 7, pp. 1049-1059, 2006.

[15] R. M. Measures, A. T. Alavie, R. Maaskant, M. Ohn, S. Karr, and S. Huang, "A structurally integrated Bragg grating laser sensing system for a carbon fiber prestressed concrete highway bridge," Smart Materials and Structures, vol. 4, no. 1, pp. 2030, 1995.

[16] R. C. Tennyson, A. A. Mufti, S. Rizkalla, G. Tadros, and B. Benmokrane, "Structural health monitoring of innovative bridges in Canada with fiber optic sensors," Smart Materials and Structures, vol. 10, no. 3, pp. 560-573, 2001.

[17] B. Benmokrane, H. Rahman, P. Mukhopadhyaya et al., "Use of fibre reinforced polymer reinforcement integrated with fibre optic sensors for concrete bridge deck slab construction," Canadian Journal of Civil Engineering, vol. 27, no. 5, pp. 928940, 2000.

[18] A. A. Mufti, G. Tadros, and P. R. Jones, "Field assessment of fibre-optic Bragg grating strain sensors in the confederation bridge," Canadian Journal of Civil Engineering, vol. 24, no. 6, pp. 963-966, 1997.

[19] R. Brönnimann, PH. M. Nellen, and U. Sennhauser, "Reliability monitoring of CFRP structural elements in bridges with fiber optic Bragg grating sensors," Journal of Intelligent Material Systems and Structures, vol. 10, no. 4, pp. 322-329, 2000.

[20] D. Inaudi and S. Vurpillot, "Monitoring of concrete bridges with long-gage fiber optic sensors," Journal of Intelligent Material Systems and Structures, vol. 10, no. 4, pp. 280-292, 2000 .
[21] D. Inaudi, A. Rufenacht, B. Von Arx, H. P. Noher, S. Vurpillot, and B. Glisic, "Monitoring of a concrete arch bridge during construction," in Smart Structures and Materials: Smart Systems for Bridges, Structures, and Highways, vol. 4696 of Proceedings of SPIE, pp. 146-153, San Diego, Calif, USA, March 2002.

[22] P. L. Fuhr, D. R. Huston, M. Nelson et al., "Fiber optic sensing of a bridge in Waterbury, Vermont," Journal of Intelligent Material Systems and Structures, vol. 10, no. 4, pp. 293-303, 2000.

[23] P. L. Fuhr and D. R. Huston, "Multiplexed fiber optic pressure and vibration sensors for hydroelectric dam monitoring," Smart Materials and Structures, vol. 2, no. 4, pp. 260-263, 1993.

[24] D. R. Huston, P. L. Fuhr, T. P. Ambrose, and D. A. Barker, "Intelligent civil structures-activities in Vermont," Smart Materials and Structures, vol. 3, no. 2, pp. 129-139, 1994.

[25] J. Ou and Z. Zhou, "Applications of optical fiber sensors of SHM in infrastructures," in Smart Sensor Phenomena, Technology, Networks, and Systems, vol. 6933 of Proceedings of SPIE, p. 10, San Diego, Calif, USA, March 2008.

[26] C. Lan, Z. Zhou, S. Sun, and J. Ou, "FBG based intelligent monitoring system of the Tianjin Yonghe Bridge," in Smart Sensor Phenomena, Technology, Networks, and Systems 2008, vol. 6933, article 693312 of Proceedings of SPIE, p. 9, San Diego, Calif, USA, March 2008.

[27] S. Liu and D. Jiang, "The application of structural health monitoring system technology FBG-based to no.2 Wuhan bridge over Yangtze river," in Photonics and Optoelectronics Meetings: Fiber Optic Communication and Sensors (POEM '08), vol. 7278 of Proceedings of SPIE, Wuhan, China, November 2008.

[28] W. R. Habel, I. Feddersen, and C. Fitschen, "Embedded quasidistributed fiber-optic sensors for the long-term monitoring of the grouting area of rock anchors in a large gravity dam," Journal of Intelligent Material Systems and Structures, vol. 10, no. 4, pp. 330-339, 2000.

[29] J. P. Newhook, B. Bakht, A. Mufti, and G. Tadros, "Monitoring of Hall's harbour wharf," in Health Monitoring and Management of Civil Infrastructure Systems, vol. 4337 of Proceedings of SPIE, pp. 234-244, March 2001.

[30] P. L. Fuhr, D. R. Huston, P. J. Kajenski, and T. P. Ambrose, "Performance and health monitoring of the Stafford Medical Building using embedded sensors," Smart Materials and Structures, vol. 1, no. 1, pp. 63-68, 1992.

[31] I. B. Kwon, C. Y. Kim, and M. Y. Choi, "Continuous measurement of temperature distributed on a building construction," in Smart Structures and Materials: Smart Systems for Bridges, Structures, and Highways, vol. 4696 of Proceedings of SPIE, pp. 273-283, March 2002.

[32] P. Rossi and F. Le Maou, "New method for detecting cracks in concrete using fibre optics," Materials and Structures, vol. 22, no. 6, pp. 437-442, 1989.

[33] C. K. Y. Leung, N. Elvin, N. Olson, T. F. Morse, and Y.-F. $\mathrm{He}$, "A novel distributed optical crack sensor for concrete structures," Engineering Fracture Mechanics, vol. 65, no. 2-3, pp. 133-148, 2000.

[34] K. T. Wan and C. K. Y. Leung, "Applications of a distributed fiber optic crack sensor for concrete structures," Sensors and Actuators A, vol. 135, no. 2, pp. 458-464, 2007.

[35] N. Elvin, C. K. Y. Leung, V. S. Sudarshanam, and S. Ezekiel, "Novel fiber optic delamination detection scheme: theoretical and experimental feasibility studies," Journal of Intelligent Material Systems and Structures, vol. 10, no. 4, pp. 314-321, 2000. 
[36] X. Gu, Z. Chen, and F. Ansari, "Method and theory for a multi-gauge distributed fiber optic crack sensor," Journal of Intelligent Material Systems and Structures, vol. 10, no. 4, pp. 266-273, 2000.

[37] X. Chen and F. Ansari, "Fiber optic stress wave sensor for detection of internal flaws in concrete structures," Journal of Intelligent Material Systems and Structures, vol. 10, no. 4, pp. 274-279, 2000.

[38] Z. Chen and A. Farhad, "Embedded fiber optic sensors for detection of acoustic emissions in structures," Acta Optica Sinica, vol. 20, no. 8, pp. 1060-1064, 2000.

[39] D. C. Betz, G. Thursby, B. Culshaw, and W. J. Staszewski, "Acousto-ultrasonic sensing using fiber Bragg gratings," Smart Materials and Structures, vol. 12, no. 1, pp. 122-128, 2003.

[40] N. R. Swamy and R. M. Wan, "Use of dynamic nondestructive test methods to monitor concrete deterioration due to alkalisilica reaction," Cement, Concrete and Aggregates, vol. 15, no. 1, pp. 32-49, 1993.

[41] M. Sansalone, J.-M. Lin, and W. B. Streett, "Determining the depth of surface-opening cracks using impact-generated stress waves and time-of-flight techniques," ACI Materials Journal, vol. 95, no. 2, pp. 168-177, 1998.

[42] Y.-C. Jung, T. Kundu, and M. R. Ehsani, "A new nondestructive inspection technique for reinforced concrete beams," $A C I$ Materials Journal, vol. 99, no. 3, pp. 292-299, 2002.

[43] P. L. Fuhr and D. R. Huston, "Corrosion detection in reinforced concrete roadways and bridges via embedded fiber optic sensors," Smart Materials and Structures, vol. 7, no. 2, pp. 217-228, 1998.

[44] R. C. Tennyson, T. Coroy, G. Duck et al., "Fibre optic sensors in civil engineering structures," Canadian Journal of Civil Engineering, vol. 27, no. 5, pp. 880-889, 2000.

[45] Y. Wang, D.-K. Liang, and B. Zhou, "Measurement of steel corrosion in concrete structures by analyzing long-period fiber grating spectrum character," Spectroscopy and Spectral Analysis, vol. 28, no. 11, pp. 2660-2664, 2008 (Chinese).

[46] P. Cosentino, B. Grossman, C. Shieh, S. Doi, H. Xi, and P. Erbland, "Fiber-optic chloride sensor development," Journal of Geotechnical Engineering, vol. 121, no. 8, pp. 610-617, 1995.

[47] W. C. Michie, B. Culshaw, M. Konstantaki et al., "Distributed $\mathrm{pH}$ and water detection using fiber-optic sensors and hydrogels," Journal of Lightwave Technology, vol. 13, no. 7, pp. 1415-1420, 1995.

[48] W. Grahn, P. Makedonski, J. Wichern, W. Kowalsky, and S. Wiese, "Fiberoptical sensors for in-situ monitoring of moisture and $\mathrm{pH}$-value in reinforced concrete," in Imaging Spectrometry VII, vol. 4480 of Proceedings of SPIE, pp. 395-403, August 2001.

[49] C. Liang, F. P. Sun, and C. A. Rogers, "Coupled electromechanical analysis of adaptive material systemsdetermination of the actuator power consumption and system energy transfer," Journal of Intelligent Material Systems and Structures, vol. 5, no. 1, pp. 12-20, 1994.

[50] J. W. Ayres, F. Lalande, Z. Chaudhry, and C. A. Rogers, "Qualitative impedance-based health monitoring of civil infrastructures," Smart Materials and Structures, vol. 7, no. 5, pp. 599-605, 1998.

[51] S. Park, C.-B. Yun, Y. Roh, and J.-J. Lee, "PZT-based active damage detection techniques for steel bridge components," Smart Materials and Structures, vol. 15, no. 4, pp. 957-966, 2006.

[52] G. Park, H. H. Cudney, and D. J. Inman, "Impedance-based health monitoring of civil structural components," Journal of Infrastructure Systems, vol. 6, no. 4, pp. 153-160, 2000.
[53] G. Park, K. Kabeya, H. H. Cudney, and D. J. Inman, "Impedance-based structural health monitoring for temperature varying applications," JSME International Journal, Series A, vol. 42, no. 2, pp. 249-258, 1999.

[54] Y. Yang, Y. Y. Lim, and C. K. Soh, "Practical issues related to the application of the electromechanical impedance technique in the structural health monitoring of civil structures. I. Experiment," Smart Materials and Structures, vol. 17, no. 3, Article ID 035008, p. 14, 2008.

[55] Y. Yang, Y. Y. Lim, and C. K. Soh, "Practical issues related to the application of the electromechanical impedance technique in the structural health monitoring of civil structures. II. Numerical verification," Smart Materials and Structures, vol. 17, no. 3, Article ID 035008, p. 12, 2008.

[56] C. K. Soh, K. K.-H. Tseng, S. Bhalla, and A. Gupta, "Performance of smart piezoceramic patches in health monitoring of a RC bridge," Smart Materials and Structures, vol. 9, no. 4, pp. 533-542, 2000.

[57] K. K. Tseng and L. Wang, "Smart piezoelectric transducers for in situ health monitoring of concrete," Smart Materials and Structures, vol. 13, no. 5, pp. 1017-1024, 2004.

[58] Y. Y. Lim, S. Bhalla, and C. K. Soh, "Structural identification and damage diagnosis using self-sensing piezo-impedance transducers," Smart Materials and Structures, vol. 15, no. 4, pp. 987-995, 2006.

[59] Y. Wen, Y. Chen, P. Li, D. Jiang, and H. Guo, "Smart concrete with embedded piezoelectric devices: implementation and characterization," Journal of Intelligent Material Systems and Structures, vol. 18, no. 3, pp. 265-274, 2007.

[60] C. S. Wang, F. Wu, and F.-K. Chang, "Structural health monitoring from fiber-reinforced composites to steelreinforced concrete," Smart Materials and Structures, vol. 10, no. 3, pp. 548-552, 2001.

[61] F. Wu and F.-K. Chang, "A built-in active sensing diagnostic system for civil infrastructure systems," in Smart Systems for Bridges, Structures, and Highways-Smart Structures and Materials, vol. 4330 of Proceedings of SPIE, pp. 27-35, March 2001.

[62] F. Wu and F. K. Chang, "Diagnosis of debonding in steelreinforced concrete with embedded piezoelectric elements," in Proceedings of the 3rd International Workshop on Structural Health Monitoring: The Demands and Challenges, F. K. Chang, Ed., pp. 670-679, CRC Press, New York, NY, USA, 2001.

[63] G. Kawiecki, "Feasibility of applying distributed piezotransducers to structural damage detection," Journal of Intelligent Material Systems and Structures, vol. 9, no. 3, pp. 189-197, 1998.

[64] M. Saafi and T. Sayyah, "Health monitoring of concrete structures strengthened with advanced composite materials using piezoelectric transducers," Composites Part B, vol. 32, no. 4, pp. 333-342, 2001.

[65] M. Q. Sun, W. J. Staszewski, R. N. Swamy, and Z. Q. Li, "Application of low-profile piezoceramic transducers for health monitoring of concrete structures," NDT and E International, vol. 41, no. 8, pp. 589-595, 2008.

[66] G. B. Song, H. C. Gu, and Y.-L. Mo, "Smart aggregates: multi-functional sensors for concrete structures-a tutorial and a review," Smart Materials and Structures, vol. 17, no. 3, Article ID 033001, 2008.

[67] Z. Li, D. Zhang, and K. Wu, "Cement-based 0-3 piezoelectric composites," Journal of the American Ceramic Society, vol. 85, no. 2, pp. 305-313, 2002. 
[68] Y. Y. Lu and Z. J. Li, "Cement-based piezoelectric sensor for acoustic emission detection in concrete structures," in Proceedings of the 11th Aerospace Division International Conference on Engineering, Science, Construction, and Operations in Challenging Environments, vol. 323, March 2008.

[69] X. Y. Zhao, H. N. Li, D. Du, and J. L. Wang, "Concrete structure monitoring based on built-in piezoelectric ceramic transducers," in Sensors and Smart Structures Technologies for Civil, Mechanical, and Aerospace Systems, vol. 6932 of Proceedings of SPIE, p. 8, March 2008.

[70] P.-W. Chen and D. D. L. Chung, "Carbon fiber reinforced concrete for smart structures capable of non-destructive flaw detection," Smart Materials and Structures, vol. 2, no. 1, pp. 22-30, 1993.

[71] P. Chen and D. D. L. Chung, "Carbon-fiber-reinforced concrete as an intrinsically smart concrete for damage assessment during dynamic loading," Journal of the American Ceramic Society, vol. 78, no. 3, pp. 816-818, 1995.

[72] D. D. L. Chung, "Self-monitoring structural materials," Materials Science and Engineering, vol. 22, no. 2, pp. 57-78, 1998.

[73] Q. Mao, B. Zhao, D. Sheng, and Z. Li, "Resistance changement of compression sensible cement speciment under different stresses," Journal Wuhan University of Technology, vol. 11, no. 3, pp. 41-45, 1996.

[74] M. Sun, Z. Li, Q. Mao, and D. Shen, "A study on thermal self-monitoring of carbon fiber reinforced concrete," Cement and Concrete Research, vol. 9, no. 5, pp. 769-771, 1999.

[75] S. Wen and D. D. L. Chung, "Carbon fiber-reinforced cement as a strain-sensing coating," Cement and Concrete Research, vol. 31, no. 4, pp. 665-667, 2001.

[76] W. Wang, H. Dai, and S. Wu, "Mechanical behavior and electrical property of CFRC-strengthened RC beams under fatigue and monotonic loading," Materials Science and Engineering A, vol. 479, no. 1-2, pp. 191-196, 2008.

[77] X. Wang and D. D. L. Chung, "Short carbon fiber reinforced epoxy coating as a piezoresistive strain sensor for cement mortar," Sensors and Actuators, A, vol. 71, no. 3, pp. 208-212, 1998.

[78] N. Muto, H. Yangagida, T. Nakatsuji et al., "Self-diagnosing performance for fracture in CFGRP-reinforced concrete," Journal of the Ceramic Society of Japan, vol. 101, no. 1176, pp. 860-866, 1993.

[79] M. Sugita, H. Yanagida, and N. Muto, "Materials design for self-diagnosis of fracture in CFGFRP composite reinforcement," Smart Materials and Structures, vol. 4, no. 1A, pp. 52-57, 1995.

[80] N. Muto, Y. Arai, S. G. Shin et al., "Hybrid composites with self-diagnosing function for preventing fatal fracture," Composites Science and Technology, vol. 61, no. 6, pp. 875-883, 2001.

[81] C. Q. Yang and Z. S. Wu, "Self-structural health monitoring function of RC structures with HCFRP sensors," Journal of Intelligent Material Systems and Structures, vol. 17, no. 10, pp. 895-906, 2006.

[82] C. Yang, Z. Wu, and Y. Zhang, "Structural health monitoring of an existing PC box girder bridge with distributed HCFRP sensors in a destructive test," Smart Materials and Structures, vol. 17, no. 3, Article ID 035032, p. 10, 2008.

[83] H. Kwun and K. A. Bartels, "Magnetostrictive sensor technology and its applications," Ultrasonics, vol. 36, no. 1-5, pp. 171-178, 1998.

[84] D. A. Khazem, H. Kwun, S. Y. Kim, and C. Dynes, "Long-range inspection of suspender ropes in suspension bridges using the magnetostrictive sensor technology," in Proceedings of the 3rd International Workshop on Structural Health Monitoring: The Demands and Challenges, F.-K. Chung, Ed., pp. 384-392, CRC Press, New York, NY, USA, 2001.

[85] W.-B. Na and T. Kundu, "EMAT-based inspection of concretefilled steel pipes for internal voids and inclusions," Journal of Pressure Vessel Technology, vol. 124, no. 3, pp. 265-272, 2002.

[86] W.-B. Na and T. Kundu, "A combination of PZT and EMAT transducers for interface inspection," Journal of the Acoustical Society of America, vol. 111, no. 5 I, pp. 2128-2139, 2002.

[87] P. Bouchilloux, N. Lhermet, and F. Claeyssen, "Electromagnetic stress sensor for bridge cables and prestressed concrete structures," Journal of Intelligent Material Systems and Structures, vol. 10, no. 5, pp. 397-401, 2000.

[88] P. Rizzo and F. L. Di Scalea, "Wavelet-based feature extraction for automatic defect classification in strands by ultrasonic structural monitoring," Smart Structures and Systems, vol. 2, no. 3, pp. 253-274, 2006. 

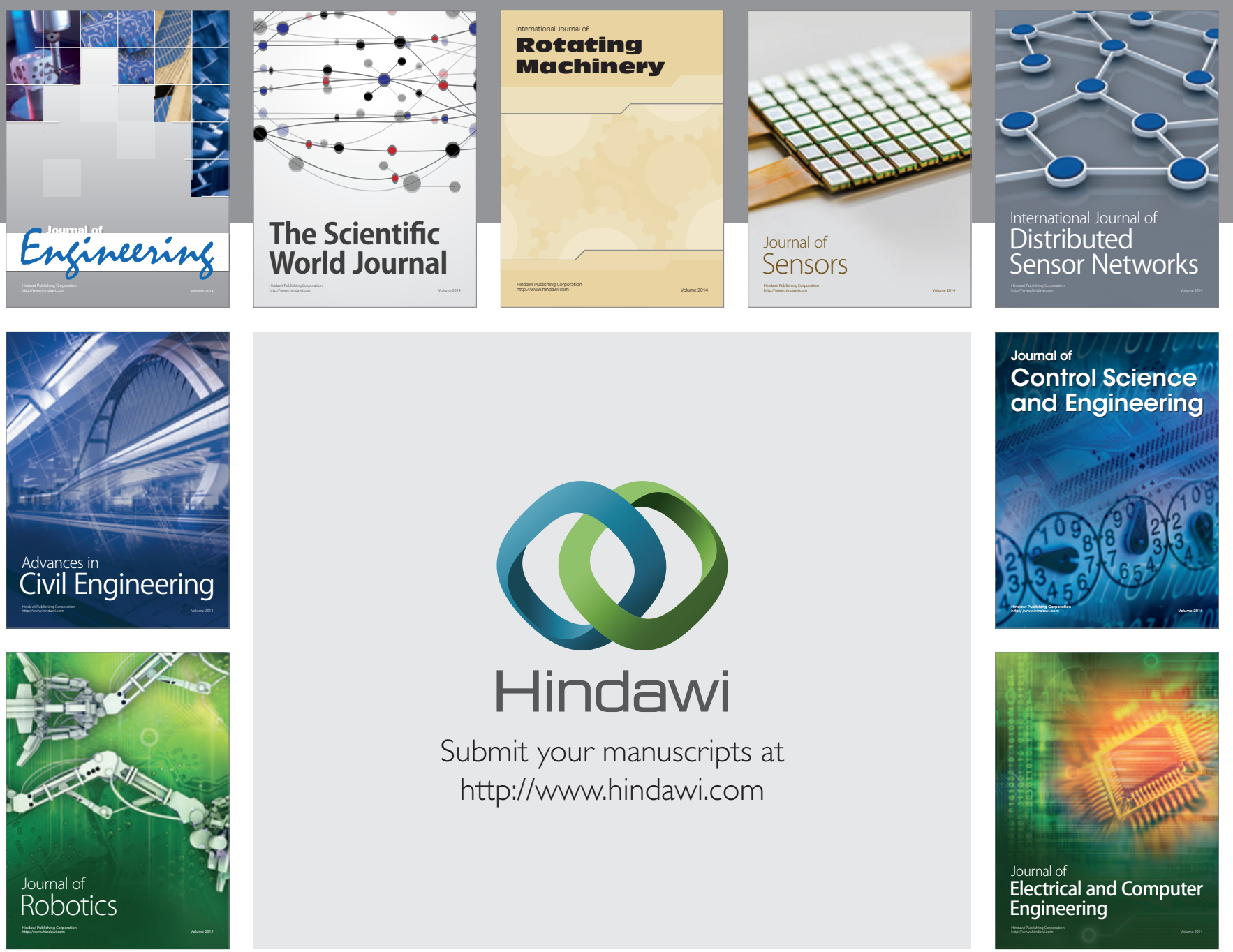

Submit your manuscripts at

http://www.hindawi.com
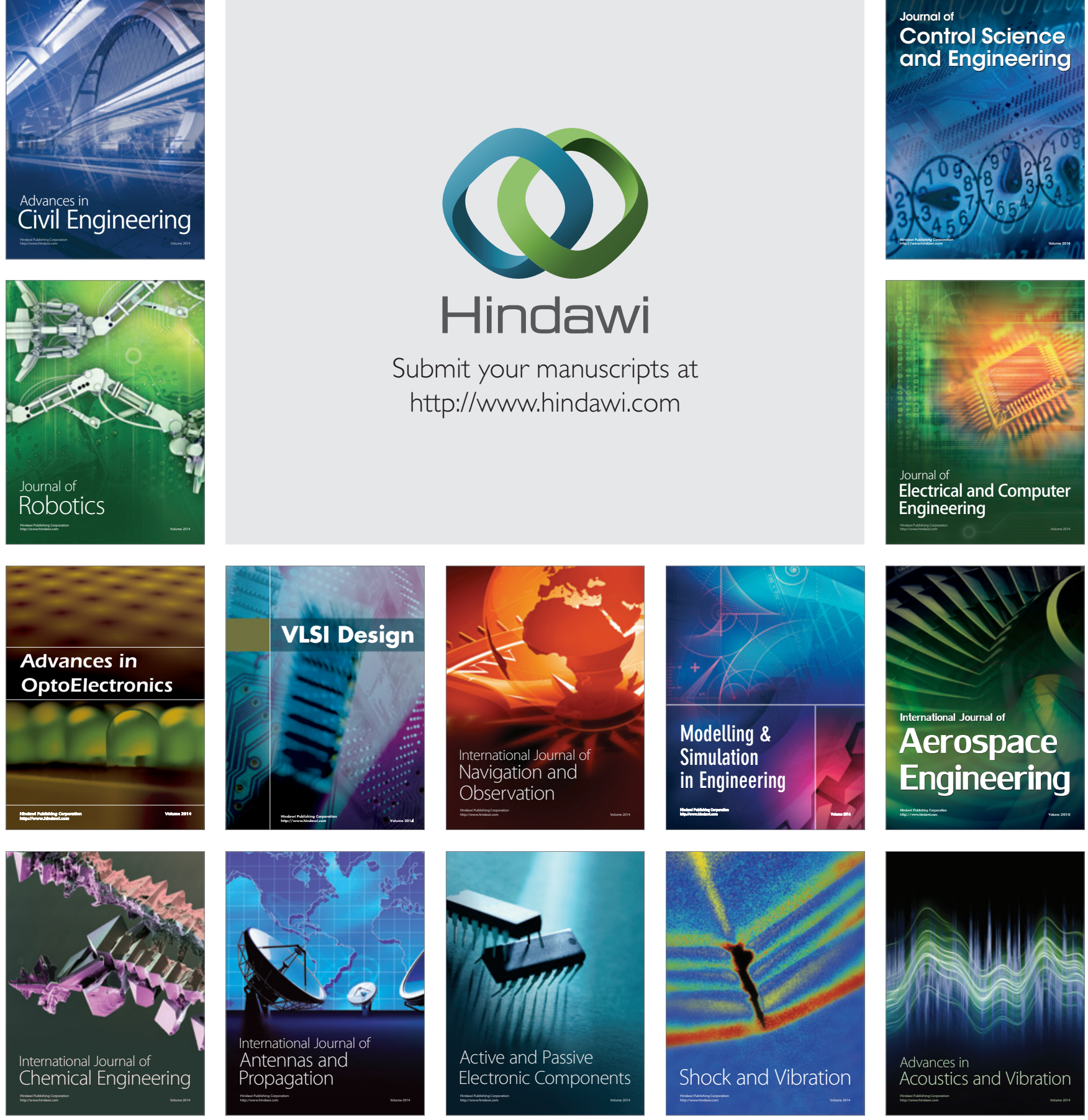